\title{
Advancing epilepsy genetics in the genomic era
}

\author{
Candace T. Myers and Heather C. Mefford
}

\begin{abstract}
Epilepsy is a group of disorders characterized by recurrent seizures, and is one of the most common neurological conditions. The genetic basis of epilepsy is clear from epidemiological studies and from rare gene discoveries in large families. The three major classes of epilepsy disorders are genetic generalized, focal and encephalopathic epilepsies, with several specific disorders within each class. Advances in genomic technologies that facilitate genome-wide discovery of both common and rare variants have led to a rapid increase in our understanding of epilepsy genetics. Copy number variant and genome-wide association studies have contributed to our understanding of the complex genetic architecture of generalized epilepsy, while genetic insights into the focal epilepsies and epileptic encephalopathies have come primarily from exome sequencing. It is increasingly clear that epilepsy is genetically heterogeneous, and novel gene discoveries have moved the field beyond the known contribution of ion channels to implicate chromatin remodeling, transcriptional regulation and regulation of the mammalian target of rapamycin (mTOR) protein in the etiology of epilepsy. Such discoveries pave the way for new therapeutics, some of which are already being studied. In this review, we discuss the rapid pace of gene discovery in epilepsy, as facilitated by genomic technologies, and highlight several novel genes and potential therapies.
\end{abstract}

\section{The genetic basis of epilepsy}

Epilepsy is defined by recurrent, unprovoked seizures due to abnormal, synchronized neuronal firing in the brain. The condition affects up to 1 in 26 individuals in the United States [1], making it one of the most common neurological conditions. Approximately $20-30 \%$ of epilepsy cases are caused by acquired conditions such as stroke, tumor or head injury, but the remaining $70-80 \%$ of cases are believed to be due to one or more genetic factors [2]. Although the definition of epilepsy suggests that it is a single disorder, it is more accurate to describe epilepsy as a group of disorders with diverse etiologies and outcomes. There are many different epilepsy syndromes that can be characterized by the seizure type(s), age of onset, developmental status, co-morbid features and etiology [3].

The epilepsies can be broadly grouped into three classes: genetic generalized epilepsy (GGE; formerly idiopathic generalized epilepsy); focal epilepsy; and epileptic encephalopathy (EE). There are then several specific syndromes within each class defined by differences in

\footnotetext{
* Correspondence: hmefford@uw.edu

Department of Pediatrics, Division of Genetic Medicine, University of Washington, Seattle, WA 98195, USA
}

specific seizure types, electroencephalogram (EEG) patterns, age of onset and disease progression. We will refer to these as primary epilepsy disorders. The GGE syndromes, characterized by generalized seizures that involve both sides of the brain, include juvenile myoclonic epilepsy and childhood absence epilepsy among others. The GGEs tend to start in childhood or adolescence and are usually associated with normal development and intellect. Focal seizures originate in one hemisphere of the brain. Examples of focal epilepsy syndromes are temporal lobe epilepsy, autosomal dominant nocturnal frontal lobe epilepsy (ADNFLE), and autosomal dominant epilepsy with auditory features. The EEs are severe, early onset conditions characterized by refractory seizures, developmental delay or regression associated with ongoing epileptic activity, and generally poor prognosis. Dravet, Ohtahara and West syndromes are some of the most well-studied EEs. Importantly, epilepsy is often a co-morbid condition in individuals with intellectual disability (ID), autism or schizophrenia and may be a feature of many metabolic conditions and genetic syndromes. The focus of this review will be on the primary epilepsies, but we will also highlight some of the advances that increase our understanding of related neurodevelopmental conditions. 
A genetic basis for epilepsy has been hypothesized for decades, but the first evidence of a genetic component emerged from epidemiological studies that reported an increased risk of epilepsy in relatives of affected individuals $[4,5]$. Studies of twins showed that monozygotic twins have a higher concordance rate for both GGE and focal epilepsy than dizygotic twins, supporting the hypothesis that epilepsy has a genetic basis [6, 7]. Human genetics approaches that applied linkage analysis and gene mapping in large families in the 1990s yielded a steady trickle of gene discoveries, beginning with the finding that mutations in CHRNA4, encoding a subunit of the nicotinic acetylcholine receptor, cause ADNFLE [8]. Mutations in other genes encoding ion channels, such as KCNQ2 in benign familial neonatal seizures [9] and SCN1A in Dravet syndrome [10], led to the "channelopathy" hypothesis, which postulates that dysfunction or dysregulation of ion channels is a common mechanism underlying epilepsy syndromes.

The emergence of genomic technologies, including chromosome microarrays and next-generation sequencing, has accelerated our understanding of the genetic architecture of the epilepsies, and the trickle of gene discoveries has increased to a flood. Importantly, these largely unbiased approaches have led to gene discoveries that expand our knowledge of critical pathways for epileptogenesis beyond the ion channels, opening the door for the development of novel therapies. These technologies have led to advances in understanding of the different genomic and genetic architectures across all the major classes of epilepsy, including uncovering a surprising overlap among seemingly different disorders. We will discuss the major advances in epilepsy genomics and genetics that have surfaced largely due to advances in these technologies.

\section{Copy number variants in epilepsy}

Copy number variants (CNVs) are deletions and duplications of stretches of DNA ranging from 1 kilobase to an entire chromosome. CNVs are an important source of normal genomic variation, but some act as risk factors or causes of disease. The development of chromosome microarrays-which include comparative genomic hybridization and SNP genotyping arrays-allowed genome-wide screening for CNVs in large cohorts. CNV studies have been carried out for GGE, focal epilepsy and EE, revealing a clear role for CNVs in each major class. Overall, rare CNVs, some of which involve known disease genes, contribute to 5-10\% of cases of childhood epilepsies [11, 12].

Most studies of GGE suggest a complex genetic architecture with oligogenic inheritance $[13,14]$. A few highly penetrant genetic risk variants have been identified, most through candidate gene studies. A major breakthrough in identifying genetic risk factors for GGE came with the application of genome-wide chromosome microarrays for genome-wide CNV detection in large cohorts of patients, the first of which revealed that large, recurrent deletions at chromosomes 15q13.3, 16p13.11 and 15q11.2 are significantly enriched in patients with GGE [15-18]. Each of these microdeletions is consistently found in $0.5-1 \%$ of patients, with the $15 \mathrm{q} 13$ microdeletion conferring the most significant risk for epilepsy (odds ratio of 68) [19]. Consistent with the complex genetic architecture of the disorder, each deletion exhibits variable inheritance patterns (de novo or inherited) and incomplete penetrance [20]. The $15 \mathrm{q} 13.3$ deletion appears to be a risk factor primarily for GGE, while the $15 \mathrm{q} 11.2$ and 16 p13.11 deletions are also found in patients with focal and other epilepsies [21]. Notably, all three deletions are known risk factors for ID, autism and schizophrenia as well, highlighting a shared genetic susceptibility for these disorders. Importantly, patients with GGE and ID are more likely to have one of these three deletions than patients with GGE and normal intellect [22]. Rare deletions involving the exons of some neuronal genes have recently been shown to increase risk for GGE, including NRXN1 [23], RBFOX1 [24] and GPHN [25].

To our knowledge, the largest study of patients with focal epilepsy carried out so far included 3812 affected individuals [21]. The 16p13.11 deletion described above was found in 23 cases $(0.6 \%)$. In addition, there was an excess of large ( $>2$ megabase) rare deletions in cases compared to controls. In the EEs, pathogenic CNVs account for approximately 3-5\% of cases $[11,26]$. Interestingly, deletions of 15q13.3, 15q11.2 and 16p13.11, important for GGE and focal epilepsy, are rarely seen in patients with $\mathrm{EE}$, highlighting the notion that the major classes of epilepsy have different genetic architectures [27]. Importantly, identifying regions of overlap among non-recurrent deletions in similarly affected patients can point to novel disease genes. This approach prompted targeted sequencing of $C H D 2$, a gene located in 15q26 deletions, and led to the discovery that de novo mutations cause an EE characterized by myoclonic seizures, photosensitivity and developmental delays [28, 29]. Targeted sequencing of $S L C 6 A 1$, one of two genes in a minimally deleted region of 3p25 microdeletions, led to the discovery of de novo mutations in $4 \%$ of patients with myoclonic astatic epilepsy [30]. SLC6A1 encodes a GABA ( $\gamma$-aminobutyric acid) transporter responsible for reuptake of GABA from the synapse. Conversely, the discovery of de novo mutations in PURA in patients with EE helped define PURA as the critical gene in patients with $5 \mathrm{q} 31.3$ deletions $[31,32]$.

\section{Genome-wide association studies}

One of the earliest genomic approaches to complex disease was to perform genome-wide association studies (GWASs), designed to identify common genetic variants 
that contribute to risk of disease. Many GWASs have been carried out for epilepsy, although most of the early studies were too small to detect an effect or did not have replicable results. A recent effort by the International League Against Epilepsy produced a meta-analysis of 12 cohorts totaling $>8000$ cases with focal epilepsy or GGE and $>26,000$ controls [33]. The analysis identified polymorphic sequence variants as risk factors for the combined cohorts (focal and GGE) in SCN1A-perhaps the most well-known epilepsy gene-and in protocadherin 7 (PCHD7), a gene not yet known to be associated with epilepsy. In addition, when analyzing GGE alone, a signal at chromosome 2p16.1 emerged and was narrowed down to the interval containing the genes vaccinia-related kinase 2 (VRK2) and Fanconi anaemia, complementation group L (FANCL); there was no significant signal when evaluating focal epilepsies alone. The results from this study highlight the complex genetic architecture of focal epilepsy and GGE and the need for continued investigation in even larger cohorts.

Another recent GWAS comes from Feenstra and colleagues, in which they identify common genetic variants associated with risk for simple febrile seizures [34]. The study compared children who had a febrile seizure after receiving the measles-mumps-rubella (MMR) vaccine, children who had febrile seizures unrelated to the MMR vaccine, and controls without febrile seizures. Of four risk loci identified for febrile seizures overall, two were in well-known epilepsy genes (SCN1A and SCN2A). The variant associated with the highest risk of febrile seizures was in the anoctamin 3 (ANO3) gene, which encodes a transmembrane protein that belongs to a family of chloride channels, and the fourth locus was an intergenic region on chromosome 12q21.33. A particularly interesting aspect of this study was the identification of two variants, one in the interferon-induced gene IFI44L and the other in the measles virus receptor CD46, which are each specific for risk for febrile seizures after the MMR vaccine, suggesting that we may someday be able to identify a subset of children at risk for vaccine-related febrile seizures.

There have been no large GWASs performed for the EEs. Although these severe disorders are thought to be due largely to highly penetrant single-gene (or CNV) mutations, it is possible that GWASs of unsolved cases could reveal additional genetic risk factors.

\section{Massively parallel sequencing in epilepsy}

The advent of next-generation (massively parallel) sequencing technology has revolutionized gene discovery in many disorders, including epilepsy. Applications of next-generation sequencing include gene panel, wholeexome and whole-genome sequencing. Gene panel and whole-exome sequencing are used most frequently for genetic testing in the clinic today and offer a rapid, affordable approach to mutation identification. Wholegenome sequencing is primarily used in the research laboratory, but will inevitably enter the clinical realm for diagnostics as it becomes more economical.

Perhaps the most significant recent advance in understanding the genetics of epilepsy has come from exome sequencing in the EEs, the most severe group of epilepsies. Because of the severity of disease, cases are usually sporadic with no other affected family members, precluding linkage analysis as a means to gene discovery. The discovery in 2001 that de novo mutations in SCN1A cause Dravet syndrome [10], one of the best-studied EEs, set the stage for the de novo paradigm for this class of disorders. Exome sequencing in single families and in both small and large cohorts has proven to be an essential tool to confirm the importance of de novo mutations, facilitate rapid gene discovery and highlight the genetic heterogeneity of this disorder. The major advances will be highlighted here, as a comprehensive discussion of the discoveries made is beyond the scope of this review.

In 2012, whole-genome sequencing in a single family with a severely affected child revealed a de novo SCN8A mutation in the proband [35]. Subsequent studies have confirmed the importance of this gene in the etiology of EE, with $>25$ cases reported with mutations in this gene since 2013 [36-39]. Most patients have a similar clinical presentation, with seizure onset at around five months of age and subsequent developmental delays and ID. In a slightly larger study, using exome sequencing in 39 patients with fever-associated epilepsies similar to Dravet syndrome, Nava and colleagues identified two de novo mutations in HCN1 [40]. Sequencing HCN1 in 157 additional affected individuals yielded four more patients with a mutation in this gene. HCN1 belongs to a family of hyperpolarization-activated, cyclic-nucleotide-gated channels that regulate neuronal excitability. Previous studies suggested that rare variants in $\mathrm{HCN} 1$ and $\mathrm{HCN} 2$ are risk factors for GGE [41]. Another study of 13 unsolved patients with Dravet syndrome revealed the importance of mutations in GABRA1 and STXBP1 [42], two genes previously implicated in other EEs. GABRA1 encodes the $\alpha_{1}$ subunit of the $\mathrm{GABA}_{\mathrm{A}}$ receptor, a multisubunit chloride channel that serves as the receptor for the GABA inhibitory neurotransmitter. STXBP1 encodes a syntaxin-binding protein that is critical for presynaptic vesicle docking and fusion. Mutations in KCNB1, a voltage-gated potassium channel, were also identified by exome sequencing in three families [43]. Other examples of recent gene discoveries are listed in Table 1.

Each of the discoveries described above adds to the growing list of genes implicated in epilepsy, and most support the channelopathy hypothesis. However, one of the distinct advantages of whole-genome technologies is the ability to use a hypothesis-free approach and discover 
Table 1 Novel epilepsy gene discoveries from 2012 to 2015

\begin{tabular}{|c|c|c|c|}
\hline Gene & Phenotype(s) & Number of cases ${ }^{a}$ & References \\
\hline \multicolumn{4}{|c|}{ Chromatin remodeling } \\
\hline CHD2 & EOEE, LGS, EE, ASD & $>20$ & {$[28,44-46,87]$} \\
\hline \multicolumn{4}{|c|}{ Ion channels and neurotransmitter receptors } \\
\hline GABRA1 & $\mathrm{DS}, \mathrm{IS}, \mathrm{JME}, \mathrm{CAE}, \mathrm{GGE}$ & $>10$ & {$[42,46,88-90]$} \\
\hline GABRB3 & IS, LGS & 4 & [46] \\
\hline GRIN2A & LKS, CSWS, BECTS, ABPE, EE & $>50$ & [91-97] \\
\hline GRIN2B & IS, LGS, FE/ID, ID, ASD & $>10$ & {$[46,49,54,98]$} \\
\hline HCN1 & EOEE & 4 & [40] \\
\hline KCNB1 & IS & 4 & {$[43,68]$} \\
\hline KCNA2 & $\mathrm{EE}$ & 6 & [99] \\
\hline KCNC1 & PME & $13^{\mathrm{b}}$ & {$[100]$} \\
\hline KCNQ2 & BFNS, EOEE, EE & $>50$ & {$[9,72,101-104]$} \\
\hline KCNT1 & MPSI, ADNFLE & 14 & {$[81,105-108]$} \\
\hline SCN8A & $\mathrm{EE}, \mathrm{EOEE}$ & $>30$ & {$[35,37-39,108]$} \\
\hline SLC6A1 & MAE & 6 & [30] \\
\hline \multicolumn{4}{|c|}{ Intracellular signaling } \\
\hline GNAO1 & OS, IS, EE & 6 & {$[68,109]$} \\
\hline SYNGAP1 & $E E, I D, A S D$ & $>20$ & {$[28,54,110,111]$} \\
\hline TBC1D24 & MPSI, DOORS, EOEE, FE + ID, FIME, PME & $>15$ & {$[100,112-118]$} \\
\hline \multicolumn{4}{|c|}{ Metabolism } \\
\hline CERSI & PME & $1^{\mathrm{a}}$ & [119] \\
\hline SLC13A5 & EOEE & $3^{\mathrm{a}}$ & [120] \\
\hline SLC25A22 & NEESBS, MPSI, EME & $4^{a}$ & {$[121-124]$} \\
\hline SLC35A2 & EOEE, IS & 8 & {$[68,125,126]$} \\
\hline \multicolumn{4}{|c|}{ Synaptic vesicle cycle } \\
\hline DNM1 & IS, LGS & 5 & {$[68]$} \\
\hline NECAP1 & EOEE & $1^{\mathrm{a}}$ & {$[127]$} \\
\hline SNAP25 & $\mathrm{EE}$ & 1 & [128] \\
\hline STX1B & Fever-associated epilepsy & 6 & [129] \\
\hline STXBP1 & EOEE, OS, IS, DS, EE & $>50$ & {$[42,130-137]$} \\
\hline \multicolumn{4}{|c|}{ mTOR signaling } \\
\hline DEPDC5 & FFEVF, ADNFLE, BECTS, FCD, HME & $>40$ & {$[58-64]$} \\
\hline MTOR & FCD & 18 & {$[66,138]$} \\
\hline \multicolumn{4}{|c|}{ Multiple functions } \\
\hline ALG13 & IS, LGS & 4 & {$[46,54,134]$} \\
\hline EEF1A2 & IS, EOEE, ASD, ID, microcephaly & 4 & {$[54-56]$} \\
\hline PURA & EOEE & 15 & {$[31,32]$} \\
\hline WWOX & EOEE, microcephaly & $8^{\mathrm{a}}$ & [139-142] \\
\hline
\end{tabular}

ABPE atypical benign partial epilepsy, ADNFLE autosomal dominant nocturnal frontal lobe epilepsy, ASD autism spectrum disorder, BECTS benign epilepsy with centrotemporal spikes, BFNS benign familial neonatal seizures, CAE childhood absence epilepsy, CSWS continuous spike and waves during sleep, DOORS deafness, onychodystrophy, osteodystrophy, mental retardation and seizures syndrome, DS Dravet syndrome, EE epileptic encephalopathy, EME early myoclonic encephalopathy, EOEE early onset epileptic encephalopathy, FE focal epilepsy, FFEVPF familial focal epilepsy with variable foci, FIME familial infantile myoclonic epilepsy, GGE genetic generalized epilepsy, HME hemimegalencephaly, ID intellectual disability, IS infantile spasms, JME juvenile myoclonic epilepsy, LGS Landau-Kleffner syndrome, MAE myoclonic astatic epilepsy, MPS/ migrating partial seizures of infancy, NEESBs neonatal epileptic encephalopathy with suppression bursts, OS Ohtahara syndrome, PME progressive myoclonus epilepsy.

${ }^{a}$ Refers to the number of families for recessive genes or isolated cases with respect to recurrent mutations.

bUnrelated probands have the same recurrent mutation (KCNC1 p.Arg320His), demonstrated to be de novo in 9/13. 
the unexpected. In epilepsy, that includes genes involved in chromatin remodeling and transcriptional regulation, synaptic vesicle trafficking, and mammalian target of rapamycin (mTOR) signaling.

A growing class of genes implicated in epilepsy and related disorders are those that code for proteins involved in chromatin remodeling and transcriptional regulation. Through targeted sequencing of candidate genes from CNV regions, we identified 5 of 500 patients with EE who had a de novo mutation in CHD2 [28]. This gene, which encodes chromodomain helicase DNA-binding protein 2, a chromatin remodeling factor, was also identified through exome sequencing in two Dravet-like cases [44]. To date, more than 20 patients with mutations in CHD2 have been identified, with the majority of mutations being confirmed de novo events [28, 29, 44-47]. The epilepsy phenotype is characterized by multiple seizures types, primarily myoclonic, and exquisite photosensitivity in most patients [29]. In addition, variants in CHD2 have been shown to be a risk factor for photosensitivity in the GGEs [48]. Targeted and whole-exome sequencing in a cohort of 580 patients with photosensitive epilepsy or photoparoxysmal response as determined by EEG revealed an overrepresentation of unique, either disruptive or predicted to be damaging, variants in CHD2. The classical photosensitive GGE-eyelid myoclonia with absenceshad the highest frequency of unique variants, with $C H D 2$ explaining as many as 3 of 36 (8.3\%) cases. Notably, mutations have also been reported in patients with autism [49] and in ID without seizures [50]. Careful phenotyping of additional patients with mutations in CHD2 will help define the phenotypic spectrum, which will undoubtedly be broader than that described for the first series of patients. CHD2 is ubiquitously expressed, and Encyclopedia of DNA Elements (ENCODE) data suggest that it acts as a transcriptional activator, although the target genes in the brain are not yet known. Mechanistic studies to identify the brain-specific function of CHD2 may yield novel drug targets for future therapies. Another gene that causes a surprisingly specific neural phenotype is the transcription factor myocyte enhancer factor $2 \mathrm{C}$ (MEF2C). While $M E F 2 C$ has important regulatory roles in other tissue types such as cardiac and skeletal muscle, it is a critical gene in neural progenitor cell differentiation and maturation, and the causative gene in $5 \mathrm{q} 14$ deletion syndrome. Haploinsufficiency can cause a range of features, including hyperkinesis, variable epilepsy, ID and autism [51], as well as atypical Rett syndrome [52, 53].

EEF1A2, which encodes the $\alpha_{2}$ subunit of eukaryotic elongation factor 1 , is another gene that merits further investigation. Recently, de novo mutations have been identified in four patients with severe early myoclonic epilepsy, hypotonia and developmental delay in three different studies [54-56]. The canonical role of EEF1A2 is translation elongation during protein synthesis, but diverse cellular functions, such as promotion of cell survival and growth, inhibition of apoptosis, and actin cytoskeletal remodeling via activation of the AKT pathway, have been reported [57].

Inroads have also been made in understanding the genetics of focal epilepsies through exome sequencing, revealing novel pathways beyond the ion channel. Two groups simultaneously reported mutations in DEPDC5 in patients with familial focal epilepsy with variable foci (FFEVF) and other focal epilepsies [58, 59]. This gene has since been implicated in various childhood focal epilepsies [60] and ADNFLE [61] as well. Surprisingly, mutations have been described in patients with focal epilepsy and brain malformations, including bottom of the sulcus dysplasia, heterotopia, focal cortical dysplasia and hemimegalencephaly [62-64]. This is a particularly important finding, as epilepsy due to brain malformations has often been classified as "acquired", or nongenetic rather than genetic, but now we must rethink traditional classification schemes. DEPDC5 is a member of the GATOR complex, a negative regulator of the mTOR pathway. mTOR is a serine/threonine kinase that converges multiple intracellular and extracellular signals to regulate cell growth, proliferation, survival, motility and metabolism. Dysregulation of mTOR signaling can cause a variety of diseases, including tuberous sclerosis (mutations in TSC1, TSC2), hemimegalencephaly (AKT3, PIK3CA, MTOR) and focal cortical dysplasia (DEPDC5, AKT3, MTOR) $[65,66]$. Consistent neurological features of these disorders include intractable epilepsy, ID and autistic features, thus implicating these genes in epileptogenesis.

Exome-sequencing studies in GGE have been less successful at identifying clear genetic risk factors or highpenetrance mutations. In the largest study of GGE to date, exome sequencing in 118 affected individuals and 242 controls revealed several candidate sequence variants that were found only in affected cases [21]. However, follow-up genotyping of 3897 candidate variants in additional cases and controls failed to identify statistically significant differences between cases and controls. Very large cohorts may be required to make progress in GGE due to the complex genetic architecture that likely underlies this class of epilepsy.

\section{Genetic heterogeneity}

With a few exceptions, most of the novel epilepsy genes that have been described recently are mutated in only a handful of patients (Table 1). While the numbers of affected individuals with mutations in a given gene will undoubtedly grow as additional patients are evaluated, it is clear that all classes of epilepsy are genetically heterogeneous. For the EEs, a recent, large trio exome study highlights this point [46]. 
The Epi4K consortium used trio exome sequencing to identify de novo mutations in patients with infantile spasms or Lennox-Gastaut syndrome (LGS) [46, 67], two classical EEs. In a study of 264 parent-child trios, a total of 329 de novo mutations in 305 genes were identified [46]. The majority of clearly causative mutations were in genes already known to cause $\mathrm{EE}$, including $S C N 1 A$, STXBP1, and CDKL5, but two new disease genes emerged: GABRB3 and $A L G 13$. GABRB3 encodes the $\beta_{3}$ subunit of the $G_{A B A}$ receptor, supporting the channelopathy hypothesis, while ALG13 encodes a subunit of the uridine diphosphate $N$-acetylglucosamine (UDP-GlcNAc) transferase that is involved in N-linked glycosylation, an essential modification for protein folding and stability. Many candidate genes from this study will need to be sequenced across larger cohorts to identify additional de novo mutations. This is exemplified by the identification of DNM1 as a causative gene of EE. The Epi4k analysis of 264 exomes identified two patients with de novo mutations in DNM1 [46], but this number did not reach statistical significance given the size of the gene and predicted sequence-specific mutation rate. By analyzing another 92 cases in collaboration with the EuroEPINOMICS consortium, three additional de novo mutations were identified, solidifying the pathogenic role of mutations in DNM1 [68]. DNM1 encodes dynamin 1, a neural-specific GTPase that localizes to the presynaptic terminal and is important for the scission of synaptic vesicles from the plasma membrane.

Mutations in numerous genes can also cause focal epilepsy syndromes, including the recently described DEPDC5, KCNT1 and GRIN2A genes, and a number of genes have been identified as risk factors for or causes of GGE. However, for both classes of epilepsy, the genes identified to date only explain a fraction of cases, suggesting that there is also considerable genetic heterogeneity in focal epilepsy and GGE.

Recent gene discoveries such as GABRB3, GRIN2A, $H C N 1, K C N A 2$, and $K C N H 1$ support the channelopathy hypothesis, and genes that encode ion channels certainly represent the largest class of disease-causing genes in epilepsy. However, other recent gene discoveries, including ALG13, EEF1A2, GNAO1, NECAP1, SNAP25, STX1B, STXBP1, PURA, and WWOX, highlight that epileptogenesis is caused by perturbations in diverse cellular pathways (Table 1), providing further evidence that epilepsy is not explained wholly as a channelopathy.

\section{Expanding the phenotypic spectrum}

There is an increasingly wide phenotypic spectrum associated with mutations in GABRA1, KCNQ2, KCNT1, $S C N 8 A, T B C 1 D 24$, and DEPDC5. Genetic modifiers and/ or environmental risk factors may influence the epilepsy subtype or severity; this will require more systematic studies in the future. Careful experiments evaluating the functional consequences of specific dominant mutations are beginning to explain some of these differences [69-71]. A recent example comes from the potassium channel subunit Kv7.2, encoded by KCNQ2, in which alterations at the same amino acid (p.Arg213Trp and p.Arg213Gln) lead to strikingly different phenotypes [69]. The Arg213Trp change caused benign familial neonatal seizures, a dominantly inherited neonatal epilepsy with a generally favorable prognosis, in contrast to the Arg213Gln change, which caused neonatal EE with severe pharmacoresistant seizures, EEG consistent with a burst-suppression pattern, macrocephaly, and neurocognitive and motor delays [69, 72]. Miceli and colleagues demonstrated that both mutations in the potassium channel subunit Kv7.2 caused a decrease in channel voltage sensitivity, but the Arg213Gln mutation had a more dramatic effect, likely explaining the more severe phenotype. Detailed mutation modeling such as this will be required to understand how molecular perturbations underlie the etiology of epilepsy syndromes.

For some genes, the phenotypic spectrum expands beyond the epilepsies to other neurodevelopmental disorders, including autism and ID. For example, although the majority of patients with mutations in STXBP1, SYNGAP1, or $C H D 2$ present with seizures, mutations have also been identified in individuals with ID and/or autism spectrum disorder but without epilepsy [49]. Mutations in $S C N 1 A$ have been found in patients from autism cohorts [73], and mutations in $S C N 2 A$ cause a range of neurodevelopmental conditions with and without seizures [74]. It is important to remember that there may be selection and phenotyping bias in large cohorts; that is, phenotype information for patients recruited to "autism" studies will focus on autistic features and subtypes whereas patients in "epilepsy" cohorts will likely have detailed seizure and EEG information available. Careful and comprehensive phenotyping of patients after a mutation is identified will help determine the full phenotypic spectrum associated with a given mutation within a gene, without such phenotypic bias.

\section{Where are the missing mutations?}

Genomic technologies have afforded tremendous progress in understanding the genetics of epilepsy, but there is still much work to be done. Despite whole-exome sequencing in trios, a large number of cases of EE remain unsolved. The combined Epi4K/EuroEPINOMICS study conservatively estimates that trio sequencing provided a clear genetic etiology in up to $12 \%$ of 356 samples. Most cases had at least one de novo coding variant; for a subset of cases, the de novo variant may be causative, although this is difficult to prove without additional cases or functional studies. Recessive mutations may explain a minority of cases but are more likely in families where 
consanguinity is present. Post-zygotic, somatic mosaic mutations are increasingly recognized as an important cause of disease across a range of disorders. In the epilepsies, many of the mutations in the mTOR pathway that have been found in patients with brain malformations are somatic mosaic mutations [75-77]. Individuals with somatic mutations may present with variable phenotypes and severity depending on how many and which cells carry the mutation. Importantly, somatic mosaic mutations are not always detectable in DNA from blood, although increasingly low levels of mosaicism can be detected through deep next-generation sequencing [76]. In some cases, the mutation may be present only in the affected tissue, which will be difficult to obtain for many epilepsies. Resection of affected tissue in focal epilepsies may shed light on how this mechanism may help define the role of mosaic mutations in epilpesy. Finally, a largely unexplored area is the impact of mutations in nonexonic DNA. Rare noncoding mutations have been identified in some human diseases and are likely to play a role in epilepsy as well. Whole-genome sequencing in trios will reveal candidate de novo variants for further exploration of this hypothesis. Sorting out the complex genetics of GGE will likely require much larger cohorts and families to understand the combination of factors that contribute to genetic risk.

\section{Clinical implications}

Establishing the genetic basis of epilepsy in a given patient is important for counseling with respect to disease prognosis, for determining recurrence risk for future pregnancies and for treatment decisions in select cases [78]. A genetic diagnosis ends the diagnostic odyssey and eliminates unnecessary medical tests, and can provide the family with the opportunity to identify others in a similar situation and connect with support groups. There has been a recent growth in family organizations for the EEs, such as the Dravet Foundation, LGS Foundation, PCDH19 Alliance, Jack Pribaz Foundation (for those with KCNQ2 mutations) and FAMILIEScn2A (SCN2A mutations), among others. These organizations are powerful patient advocates, providing information and support to affected families; in addition, some family organizations play an important role in funding research.

The genetic heterogeneity of epilepsy influences genetic testing, as testing one gene at a time is no longer a practical approach. The development of gene panels and the introduction of exome sequencing for clinical diagnostics now provide more comprehensive and affordable options for testing and should be implemented early in the diagnostic process. Chromosome microarrays should be considered in severe cases and in GGE with comorbid features, where the likelihood of finding a disease-associated CNV is highest.
Beyond diagnostics, a major goal of genetic studies is to identify novel drug targets and to be able to make treatment choices based on the genetic cause of disease -an approach termed precision medicine. This will not be a simple task given the genetic complexity of epilepsy, in which mutations in different genes cause syndromes that are clinically indistinguishable, and mutations in a single gene, such as $S C N 1 A$, can cause a range of phenotypes varying from febrile seizures to severe EEs. However, recent reports offer the first insights into the power of precision medicine in treating epilepsy [79, 80]. Exome sequencing identified a heterozygous missense mutation in KCNT1 (c.1283G > A; p.Arg428Gln) in a child with migrating partial seizures of infancy (MPSI); the same mutation had been previously reported in three other patients with MPSI. Functional studies in Xenopus oocytes demonstrated that the mutant protein caused a hyperactive channel [81], and that the effects of the mutation could be partially reversed by quinidine, an antiarrhythmic drug that is a partial antagonist of the potassium channel encoded by KCNT1 [70, 82]. Administration of oral quinidine in this child correlated with diminished or absent seizure activity and an improvement in psychomotor skills. Similarly, the administration of memantine, a US Food and Drug Administration-approved NMDA ( $N$-methyl-D-aspartate) receptor antagonist, greatly reduced seizure activity in a patient with early onset EE caused by a de novo missense mutation in GRIN2A (p.Leu812Met) [80]. In vitro experiments testing for activity of the mutant receptor were performed prior to administration of the drug, an important point as not all mutations affect a protein equally. In vitro experiments performed on another GRIN2A mutant protein (p.Asn615Lys), which was the genetic cause of another child's early onset EE, demonstrated that this mutation had a different effect on protein function entirely. GRIN2A encodes a subunit of the NMDA receptor, which is an ion channel that is activated by glutamate. Under normal conditions of synaptic transmission, very few ions pass through the channel because $\mathrm{Mg}^{2+}$ blocks the pore. Upon receptor activation, $\mathrm{Mg}^{2+}$ is displaced, which allows $\mathrm{Ca}^{2+}$ and other cations to move into the cell. A dysfunctional NMDA receptor can cause excess calcium influx into the cell and neurotoxicity. The Leu812Met change caused a hyperactive receptor, while the Asn615Lys mutation had no effect on receptor activity and acted through loss of the $\mathrm{Mg}^{2}$ ${ }^{+}$block. Although both mutations resulted in an increased flow of current, leading to excessive excitatory drive and early onset EE, it was important to consider the different pathological mechanisms and drug targets when deciding treatment options.

These studies highlight the importance of obtaining a molecular diagnosis early in development when possible, 
the use of cell culture and animal models to aid in the interpretation of the functional consequences of a mutation, and the need for rigorous clinical trials to standardize dosing and evaluate potential side effects of treatment. Other monogenic epilepsies for which a molecular diagnosis may influence the choice of antiepileptic drugs are KCNQ2-related epilepsies and the use of ezogabine [83, 84], SCN1A-related Dravet syndrome and the use of clemizole [85], and DEPDC5 and the use of the rapamycin derivative everolimus, which has already been effective in early clinical trials [86].

\section{Conclusions and future directions}

Advances in DNA sequencing and interpretation of genetic variation are rapidly changing our understanding of the causes of epilepsy and its clinical management. It is unlikely that an individual gene will explain a large proportion of the GGEs, so efforts should be made to sequence large cohorts to gain broad insight into the mechanisms of epileptogenesis. Exome sequencing of trios has revealed the prominence of de novo mutations as a genetic cause of severe epilepsies, indicating that even in the absence of a family history, a genetic cause should be considered. Another important point to be taken away from the next-generation sequencing experiments is the diverse classes of genes that are emerging as being implicated in epilepsy. The recent surge of novel findings moves beyond the channelopathy hypothesis, implicating pathways that regulate synaptic vesicle trafficking, mTOR signaling, chromatin remodeling and transcriptional regulation, which offer new insights into disease-causing mechanisms and provide novel avenues for therapeutics. Despite recent advances, there are many genetic mysteries that remain to be unraveled. As wholegenome sequencing becomes more prevalent, the pace of discovery is likely to accelerate once again. Collaborations that include large cohorts and the sharing of research data will expedite gene discovery across all types of epilepsy, and central repositories for large-scale sequencing projects and epilepsy-specific findings will aid in the interpretation of rare variations. Finally, centralized variant databases and streamlined approaches to functional studies will move the field closer to translating genetic discoveries to directed therapies as we enter the era of precision medicine.

\footnotetext{
Abbreviations

ABPE: Atypical benign partial epilepsy; ADNFLE: Autosomal dominant nocturnal frontal lobe epilepsy; ASD: Autism spectrum disorder; BECTS: Benign epilepsy with centrotemporal spikes; BFNS: Benign familial neonatal seizures; CAE: Childhood absence epilepsy; CNV: Copy number variation; CSWS: Continuous spike and waves during sleep; DOORS: Deafness, onychodystrophy, osteodystrophy, mental retardation and seizures syndrome; DS: Dravet syndrome; EE: Epileptic encephalopathy; EEG: Electroencephalogram; EME: Early myoclonic encephalopathy; ENCODE: Encyclopedia of DNA Elements; EOEE: Early onset epileptic encephalopathy; FE: Focal epilepsy; FFEVPF: Familial focal epilepsy with
}

variable foci; FIME: Familial infantile myoclonic epilepsy; GGE: Genetic generalized epilepsy; GWAS: Genome-wide association study; HME: Hemimegalencephaly; ID: Intellectual disability; IS: Infantile spasms; JME: Juvenile myoclonic epilepsy; LGS: Landau-Kleffner syndrome; MAE: Myoclonic astatic epilepsy; MMR: Measles-mumps-rubella vaccine; MPSI: Migrating partial seizures of infancy; NEESBs: Neonatal epileptic encephalopathy with suppression bursts; OS: Ohtahara syndrome; PME: Progressive myoclonus epilepsy.

\section{Competing interests}

The authors declare that they have no competing interests.

\section{Authors' information}

HCM is a physician scientist at the University of Washington whose research focuses on gene discovery in pediatric disorders including severe epilepsies. CTM is a postdoctoral fellow carrying out exome and targeted candidate gene sequencing in epileptic encephalopathy.

\section{Acknowledgments}

HCM receives funding from the National Institutes of Health.

Published online: 25 August 2015

\section{References}

1. England MJ, Liverman CT, Schultz AM, Strawbridge LM. Epilepsy across the spectrum: promoting health and understanding. Washington DC: National Academies Press; 2012

2. Hildebrand MS, Dahl HH, Damiano JA, Smith RJ, Scheffer IE, Berkovic SF. Recent advances in the molecular genetics of epilepsy. J Med Genet. 2013;50:271-9.

3. Berg AT, Berkovic SF, Brodie MJ, Buchhalter J, Cross JH, van Emde BW, et al Revised terminology and concepts for organization of seizures and epilepsies: report of the ILAE Commission on Classification and Terminology, 2005-2009. Epilepsia. 2010;51:676-85.

4. Ottman R, Annegers JF, Hauser WA, Kurland LT. Seizure risk in offspring of parents with generalized versus partial epilepsy. Epilepsia. 1989;30:157-61.

5. Annegers JF, Hauser WA, Anderson VE, Kurland LT. The risks of seizure disorders among relatives of patients with childhood onset epilepsy. Neurology. 1982;32:174-9.

6. Berkovic SF, Howell RA, Hay DA, Hopper JL. Epilepsies in twins: genetics of the major epilepsy syndromes. Ann Neurol. 1998;43:435-45.

7. Vadlamudi L, Andermann E, Lombroso CT, Schachter SC, Milne RL, Hopper $J$, et al. Epilepsy in twins: insights from unique historical data of William Lennox. Neurology. 2004;62:1127-33.

8. Steinlein OK, Mulley JC, Propping P, Wallace RH, Phillips HA, Sutherland GR, et al. A missense mutation in the neuronal nicotinic acetylcholine receptor alpha 4 subunit is associated with autosomal dominant nocturnal frontal lobe epilepsy. Nat Genet. 1995;11:201-3.

9. Singh NA, Charlier C, Stauffer D, DuPont BR, Leach RJ, Melis R, et al. A novel potassium channel gene, KCNQ2, is mutated in an inherited epilepsy of newborns. Nat Genet. 1998;18:25-9.

10. Claes L, Del-Favero J, Ceulemans B, Lagae L, Van Broeckhoven C. De Jonghe Pet. De novo mutations in the sodium-channel gene SCN1A cause severe myoclonic epilepsy of infancy. Am J Hum Genet. 2001;68:1327-32.

11. Mefford HC, Yendle SC, Hsu C, Cook J, Geraghty E, MCMahon JM, et al. Rare copy number variants are an important cause of epileptic encephalopathies. Ann Neurol. 2011;70:974-85.

12. Olson H, Shen Y, Avallone J, Sheidley BR, Pinsky R, Bergin AM, et al. Copy number variation plays an important role in clinical epilepsy. Ann Neurol. 2014;75:943-58.

13. Marini C, Scheffer IE, Crossland KM, Grinton BE, Phillips FL, McMahon JM, et al. Genetic architecture of idiopathic generalized epilepsy: clinical genetic analysis of 55 multiplex families. Epilepsia. 2004;45:467-78.

14. Hempelmann A, Taylor KP, Heils A, Lorenz S, Prud'homme JF, Nabbout R, et al. Exploration of the genetic architecture of idiopathic generalized epilepsies. Epilepsia. 2006:47:1682-90.

15. de Kovel CG, Trucks H, Helbig I, Mefford HC, Baker C, Leu C, et al. Recurrent microdeletions at $15 q 11.2$ and 16 p13.11 predispose to idiopathic generalized epilepsies. Brain. 2010;133:23-32. 
16. Helbig I, Mefford HC, Sharp AJ, Guipponi M, Fichera M, Franke A, et al. 15 q13.3 microdeletions increase risk of idiopathic generalized epilepsy. Nat Genet. 2009;41:160-2.

17. Mefford HC, Muhle H, Ostertag P, von Spiczak S, Buysse K, Baker C, et al. Genome-wide copy number variation in epilepsy: novel susceptibility loci in idiopathic generalized and focal epilepsies. PLoS Genet. 2010;6: e1000962.

18. Lal D, Ruppert AK, Trucks H, Schulz H, de Kovel CG, Kasteleijn-Nolst Trenité $D$, et al. Burden analysis of rare microdeletions suggests a strong impact of neurodevelopmental genes in genetic generalised epilepsies. PLoS Genet. 2015;11:e1005226

19. Dibbens LM, Mullen S, Helbig I, Mefford HC, Bayly MA, Bellows S, et al. Familial and sporadic 15q13.3 microdeletions in idiopathic generalized epilepsy: precedent for disorders with complex inheritance. Hum Mol Genet. 2009;18:3626-31

20. Helbig I, Hodge SE, Ottman R. Familial cosegregation of rare genetic variants with disease in complex disorders. Eur J Hum Genet. 2013;21:444-50.

21. Heinzen EL, Radtke RA, Urban TJ, Cavalleri GL. Depondt C, Need AC, et al. Rare deletions at 16p13.11 predispose to a diverse spectrum of sporadic epilepsy syndromes. Am J Hum Genet. 2010;86:707-18.

22. Mullen SA, Carvill GL, Bellows S, Bayly MA, Trucks H, Lal D, et al. Copy number variants are frequent in genetic generalized epilepsy with intellectual disability. Neurology. 2013;81:1507-14.

23. Moller RS, Weber YG, Klitten LL, Trucks H, Muhle H, Kunz WS, et al. Exondisrupting deletions of NRXN1 in idiopathic generalized epilepsy. Epilepsia. 2013;54:256-64

24. Lal D, Trucks H, Møller RS, Hjalgrim H, Koeleman BP, de Kovel CG, et al. Rare exonic deletions of the RBFOX1 gene increase risk of idiopathic generalized epilepsy. Epilepsia. 2013;54:265-71.

25. Lionel AC, Vaags AK, Sato D, Gazzellone MJ, Mitchell EB, Chen HY, et al. Rare exonic deletions implicate the synaptic organizer Gephyrin (GPHN) in risk for autism, schizophrenia and seizures. Hum Mol Genet. 2013;22:2055-66.

26. Epilepsy Phenome/Genome Project \& Epi4K Consortium. Copy number variant analysis from exome data in 349 patients with epileptic encephalopathy. Ann Neurol. 2015;78:323-8.

27. Mefford HC. CNVs in epilepsy. Curr Genet Med Rep. 2014;2:162-7.

28. Carvill GL, Heavin SB, Yendle SC, McMahon JM, O'Roak BJ, Cook J, et al. Targeted resequencing in epileptic encephalopathies identifies de novo mutations in CHD2 and SYNGAP1. Nat Genet. 2013:45:825-30.

29. Thomas RH, Zhang LM, Carvill GL, Archer JS, Heavin SB, Mandelstam SA, et al. CHD2 myoclonic encephalopathy is frequently associated with selfinduced seizures. Neurology. 2015;84:951-8.

30. Carvill GL, McMahon JM, Schneider A, Zemel M, Myers CT, Saykally J, et al. Mutations in the GABA transporter SLC6A1 cause epilepsy with myoclonicatonic seizures. Am J Hum Genet. 2015:96:808-15.

31. Lalani SR, Zhang J, Schaaf CP, Brown CW, Magoulas P, Tsai AC, et al. Mutations in PURA cause profound neonatal hypotonia, seizures, and encephalopathy in 5q31.3 microdeletion syndrome. Am J Hum Genet. 2014;95:579-83.

32. Hunt D, Leventer RJ, Simons C, Taft R, Swoboda KJ, Gawne-Cain M, et al. Whole exome sequencing in family trios reveals de novo mutations in PURA as a cause of severe neurodevelopmental delay and learning disability. J Med Genet. 2014;51:806-13.

33. International League Against Epilepsy Consortium on Complex Epilepsies. Genetic determinants of common epilepsies: a meta-analysis of genomewide association studies. Lancet Neurol. 2014;13:893-903.

34. Feenstra B, Pasternak B, Geller F, Carstensen L, Wang T, Huang F, et al. Common variants associated with general and MMR vaccine-related febrile seizures. Nat Genet. 2014;46:1274-82.

35. Veeramah KR, O'Brien JE, Meisler MH, Cheng X, Dib-Haij SD, Waxman SG, et al. De novo pathogenic SCN8A mutation identified by whole-genome sequencing of a family quartet affected by infantile epileptic encephalopathy and SUDEP. Am J Hum Genet. 2012;90:502-10.

36. Larsen J, Carvill GL, Gardella E, Kluger G, Schmiedel G, Barisic N, et al. The phenotypic spectrum of SCN8A encephalopathy. Neurology. 2015;84:480-9

37. Ohba C, Kato M, Takahashi S, Lerman-Sagie T, Lev D, Terashima H, et al. Early onset epileptic encephalopathy caused by de novo SCN8A mutations. Epilepsia. 2014;55:994-1000.

38. de Kovel CG, Meisler MH, Brilstra EH, van Berkestijn FM, van't Slot R, van Lieshout S, et al. Characterization of a de novo SCN8A mutation in a patient with epileptic encephalopathy. Epilepsy Res. 2014;108:1511-8.
39. Estacion M, O'Brien JE, Conravey A, Hammer MF, Waxman SG, Dib-Hajj SD, et al. A novel de novo mutation of SCN8A (Nav1.6) with enhanced channel activation in a child with epileptic encephalopathy. Neurobiol Dis. 2014;69:117-23.

40. Nava C, Dalle C, Rastetter A, Striano P, de Kovel CG, Nabbout R, et al. De novo mutations in HCN1 cause early infantile epileptic encephalopathy. Nat Genet. 2014;46:640-5.

41. Tang B, Sander T, Craven KB, Hempelmann A, Escayg A. Mutation analysis of the hyperpolarization-activated cyclic nucleotide-gated channels HCN1 and HCN2 in idiopathic generalized epilepsy. Neurobiol Dis. 2008;29:59-70.

42. Carvill GL, Weckhuysen S, McMahon JM, Hartmann C, Møller RS, Hjalgrim H, et al. GABRA1 and STXBP1: novel genetic causes of Dravet syndrome. Neurology. 2014;82:1245-53.

43. Torkamani A, Bersell K, Jorge BS, Bjork Jr RL, Friedman JR, Bloss CS, et al. De novo KCNB1 mutations in epileptic encephalopathy. Ann Neurol. 2014:76:529-40.

44. Suls A, Jaehn JA, Kecskés A, Weber Y, Weckhuysen S, Craiu DC, et al. De novo loss-of-function mutations in CHD2 cause a fever-sensitive myoclonic epileptic encephalopathy sharing features with Dravet syndrome. Am J Hum Genet. 2013;93:967-75.

45. Lund C, Brodtkorb E, Øye AM, Røsby O, Selmer KK. CHD2 mutations in Lennox-Gastaut syndrome. Epilepsy Behav. 2014;33:18-21.

46. Epi4K Consortium \& Epilepsy Phenome/Genome Project. De novo mutations in epileptic encephalopathies. Nature. 2013;501:217-21.

47. Neale BM, Kou Y, Liu L, Ma'ayan A, Samocha KE, Sabo A, et al. Patterns and rates of exonic de novo mutations in autism spectrum disorders. Nature. 2012;485:242-5

48. Galizia EC, Myers CT, Leu C, de Kovel CG, Afrikanova T, Cordero-Maldonado $\mathrm{ML}$, et al. CHD2 variants are a risk factor for photosensitivity in epilepsy. Brain. 2015:138:1198-207.

49. O'Roak BJ, Stessman HA, Boyle EA, Witherspoon KT, Martin B, Lee C, et al Recurrent de novo mutations implicate novel genes underlying simplex autism risk. Nat Commun. 2014;5:5595.

50. Hamdan FF, Srour M, Capo-Chichi JM, Daoud H, Nassif C, Patry L, et al. De novo mutations in moderate or severe intellectual disability. PLoS Genet. 2014;10:e1004772.

51. Paciorkowski AR, Traylor RN, Rosenfeld JA, Hoover JM, Harris CJ, Winter S, et al. MEF2C haploinsufficiency features consistent hyperkinesis, variable epilepsy, and has a role in dorsal and ventral neuronal developmental pathways. Neurogenetics. 2013;14:99-111.

52. Zweier M, Gregor A, Zweier C, Engels $H$, Sticht $H$, Wohlleber $E$, et al. Mutations in MEF2C from the $5 q 14.3 q 15$ microdeletion syndrome region are a frequent cause of severe mental retardation and diminish MECP2 and CDKL5 expression. Hum Mutat. 2010;31:722-33.

53. Lambert L, Bienvenu T, Allou L, Valduga M, Echenne B, Diebold B, et al. MEF2C mutations are a rare cause of Rett or severe Rett-like encephalopathies. Clin Genet. 2012;82:499-501.

54. de Ligt J, Willemsen MH, van Bon BW, Kleefstra T, Yntema HG, Kroes T, et al. Diagnostic exome sequencing in persons with severe intellectual disability. N Engl J Med. 2012;367:1921-9.

55. Nakajima J, Okamoto N, Tohyama J, Kato M, Arai H, Funahashi O, et al. De novo EEF1A2 mutations in patients with characteristic facial features, intellectual disability, autistic behaviors and epilepsy. Clin Genet. 2014:87:356-61.

56. Veeramah KR, Johnstone L, Karafet TM, Wolf D, Sprissler R, Salogiannis J, et al. Exome sequencing reveals new causal mutations in children with epileptic encephalopathies. Epilepsia. 2013;54:1270-81.

57. Abbas W, Kumar A, Herbein G. The eEF1A proteins: at the crossroads of oncogenesis, apoptosis, and viral infections. Front Oncol. 2015;5:75.

58. Dibbens LM, de Vries B, Donatello S, Heron SE, Hodgson BL, Chintawar S, et al. Mutations in DEPDC5 cause familial focal epilepsy with variable foci. Nat Genet. 2013;45:546-51.

59. Ishida S, Picard F, Rudolf G, Noé E, Achaz G, Thomas P, et al. Mutations of DEPDC5 cause autosomal dominant focal epilepsies. Nat Genet. 2013;45:552-5.

60. Lal D, Reinthaler EM, Schubert J, Muhle H, Riesch E, Kluger G, et al. DEPDC5 mutations in genetic focal epilepsies of childhood. Ann Neurol. 2014;75:788-92.

61. Picard F, Makrythanasis P, Navarro V, Ishida S, de Bellescize J, Ville D, et al. DEPDC5 mutations in families presenting as autosomal dominant nocturnal frontal lobe epilepsy. Neurology. 2014;82:2101-6.

62. Scheffer IE, Heron SE, Regan BM, Mandelstam S, Crompton DE, Hodgson BL, et al. Mutations in mammalian target of rapamycin regulator DEPDC5 cause focal epilepsy with brain malformations. Ann Neurol. 2014;75:782-7. 
63. Baulac S, Ishida S, Marsan E, Miquel C, Biraben A, Nguyen DK, et al. Familial focal epilepsy with focal cortical dysplasia due to DEPDC5 mutations. Ann Neurol. 2015;77:675-83.

64. D'Gama AM, Geng Y, Couto JA, Martin B, Boyle EA, LaCoursiere CM, et al. Mammalian target of rapamycin pathway mutations cause hemimegalencephaly and focal cortical dysplasia. Ann Neurol. 2015;77:720-5

65. Crino PB. mTOR signaling in epilepsy: insights from malformations of cortical development. Cold Spring Harb Perspect Med. 2015;5:a022442.

66. Lim JS, Kim WI, Kang HC, Kim SH, Park AH, Park EK, et al. Brain somatic mutations in MTOR cause focal cortical dysplasia type II leading to intractable epilepsy. Nat Med. 2015;21:395-400.

67. The Epi4K Consortium. Epi4K: gene discovery in 4,000 genomes. Epilepsia. 2012;53:1457-67.

68. EuroEPINOMICS-RES Consortium. Epilepsy Phenome/Genome Project, and Epi4K Consortium. De novo mutations in synaptic transmission genes including DNM1 cause epileptic encephalopathies. Am J Hum Genet. 2014;95:360-70.

69. Miceli F, Soldovieri MV, Ambrosino P, Barrese V, Migliore M, Cilio MR, et al. Genotype-phenotype correlations in neonatal epilepsies caused by mutations in the voltage sensor of $K_{\mathrm{v}} 7.2$ potassium channel subunits. Proc Natl Acad Sci U S A. 2013;110:4386-91.

70. Milligan CJ, Li M, Gazina EV, Heron SE, Nair U, Trager C, et al. KCNT1 gain of function in 2 epilepsy phenotypes is reversed by quinidine. Ann Neurol. 2014;75:581-90.

71. Miceli F, Soldovieri MV, Ambrosino P, De Maria M, Migliore M, Migliore R, et al. Early-onset epileptic encephalopathy caused by gain-of-function mutations in the voltage sensor of Kv7.2 and Kv7.3 potassium channe subunits. J Neurosci. 2015:35:3782-93.

72. Weckhuysen S, Mandelstam S, Suls A, Audenaert D, Deconinck T, Claes LR, et al. KCNQ2 encephalopathy: emerging phenotype of a neonatal epileptic encephalopathy. Ann Neurol. 2012:71:15-25.

73. O'Roak BJ, Vives L, Girirajan S, Karakoc E, Krumm N, Coe BP, et al. Sporadic autism exomes reveal a highly interconnected protein network of de novo mutations. Nature. 2012;485:246-50.

74. Krumm N, O'Roak BJ, Shendure J, Eichler EE. A de novo convergence of autism genetics and molecular neuroscience. Trends Neurosci. 2014:37:95-105.

75. Lee JH, Huynh M, Silhavy JL, Kim S, Dixon-Salazar T, Heiberg A, et al. De novo somatic mutations in components of the PI3K-AKT3-mTOR pathway cause hemimegalencephaly. Nat Genet. 2012;44:941-5.

76. Jamuar SS, Lam AT, Kircher M, D'Gama AM, Wang J, Barry BJ, et al. Somatic mutations in cerebral cortical malformations. N Engl J Med. 2014;371:733-43

77. Riviere JB, Mirzaa GM, O'Roak BJ, Beddaoui M, Alcantara D, Conway RL, et al. De novo germline and postzygotic mutations in AKT3, PIK3R2 and PIK3CA cause a spectrum of related megalencephaly syndromes. Nat Genet. 2012;44:934-40.

78. Poduri A, Sheidley BR, Shostak S, Ottman R. Genetic testing in the epilepsies-developments and dilemmas. Nat Rev Neurol. 2014;10:293-9.

79. Bearden D, Strong A, Ehnot J, DiGiovine M, Dlugos D, Goldberg EM. Targeted treatment of migrating partial seizures of infancy with quinidine. Ann Neurol. 2014:76:457-61.

80. Pierson TM, Yuan H, Marsh ED, Fuentes-Fajardo K, Adams DR, Markello T, et al. GRIN2A mutation and early-onset epileptic encephalopathy: personalized therapy with memantine. Ann Clin Transl Neurol. 2014;1:190-8.

81. Barcia G, Fleming MR, Deligniere A, Gazula VR, Brown MR, Langouet M, et al. De novo gain-of-function KCNT1 channel mutations cause malignant migrating partial seizures of infancy. Nat Genet. 2012;44:1255-9.

82. Yang B, Gribkoff VK, Pan J, Damagnez V, Dworetzky SI, Boissard CG, et al. Pharmacological activation and inhibition of Slack (Slo2.2) channels. Neuropharmacology. 2006;51:896-906.

83. Hu HN, Zhou PZ, Chen F, Li M, Nan FJ, Gao ZB. Discovery of a retigabine derivative that inhibits KCNQ2 potassium channels. Acta Pharmacol Sin. 2013;34:1359-66.

84. Orhan G, Bock M, Schepers D, llina El, Reichel SN, Löffler $H$, et al. Dominant-negative effects of KCNQ2 mutations are associated with epileptic encephalopathy. Ann Neurol. 2014;75:382-94.

85. Baraban SC, Dinday MT, Hortopan GA. Drug screening in Scn1a zebrafish mutant identifies clemizole as a potential Dravet syndrome treatment. Nat Commun. 2013:4:2410
86. Krueger DA, Wilfong AA, Holland-Bouley K, Anderson AE, Agricola K, Tudor $C$, et al. Everolimus treatment of refractory epilepsy in tuberous sclerosis complex. Ann Neurol. 2013;74:679-87.

87. Chenier S, Yoon G, Argiropoulos B, Lauzon J, Laframboise R, Ahn JW, et al, CHD2 haploinsufficiency is associated with developmental delay, intellectual disability, epilepsy and neurobehavioural problems. J Neurodev Disord. 2014;6:9.

88. Cossette $\mathrm{P}$, Liu L, Brisebois K, Dong H, Lortie A, Vanasse M, et al. Mutation of GABRA1 in an autosomal dominant form of juvenile myoclonic epilepsy. Nat Genet. 2002:31:184-9.

89. Lachance-Touchette P, Brown P, Meloche C, Kinirons P, Lapointe L, Lacasse

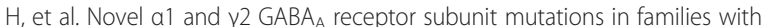
idiopathic generalized epilepsy. Eur J Neurosci. 2011;34:237-49.

90. Maljevic S, Krampfl K, Cobilanschi J, Tilgen N, Beyer S, Weber YG, et al. A mutation in the $\mathrm{GABA}_{\mathrm{A}}$ receptor $\boldsymbol{a}_{1}$-subunit is associated with absence epilepsy. Ann Neurol. 2006;59:983-7

91. Carvill GL, Regan BM, Yendle SC, O'Roak BJ, Lozovaya N, Bruneau N, et al GRIN2A mutations cause epilepsy-aphasia spectrum disorders. Nat Genet. 2013:45:1073-6.

92. DeVries SP, Patel AD. Two patients with a GRIN2A mutation and childhoodonset epilepsy. Pediatr Neurol. 2013:49:482-5.

93. Lemke JR, Lal D, Reinthaler EM, Steiner I, Nothnagel M, Alber M, et al. Mutations in GRIN2A cause idiopathic focal epilepsy with rolandic spikes. Nat Genet. 2013;45:1067-72.

94. Lesca G, Rudolf G, Bruneau N, Lozovaya N, Labalme A, Boutry-Kryza N, et al. GRIN2A mutations in acquired epileptic aphasia and related childhood focal epilepsies and encephalopathies with speech and language dysfunction. Nat Genet. 2013:45:1061-6.

95. Venkateswaran S, Myers KA, Smith AC, Beaulieu CL, Schwartzentruber JA. FORGE Canada Consortium, et al. Whole-exome sequencing in an individual with severe global developmental delay and intractable epilepsy identifies a novel, de novo GRIN2A mutation. Epilepsia. 2014:55:e75-9.

96. Conroy J, McGettigan PA, McCreary D, Shah N, Collins K, Parry-Fielder B, et al. Towards the identification of a genetic basis for Landau-Kleffner syndrome. Epilepsia. 2014;55:858-65.

97. Dyment DA, Tétreault M, Beaulieu CL, Hartley T, Ferreira P, Chardon JW, et al. Whole-exome sequencing broadens the phenotypic spectrum of rare pediatric epilepsy: a retrospective study. Clin Genet. 2015;88:34-40

98. Lemke JR, Hendrickx R, Geider K, Laube B, Schwake M, Harvey RJ, et al. GRIN2B mutations in West syndrome and intellectual disability with focal epilepsy. Ann Neurol. 2014;75:147-54.

99. Syrbe S, Hedrich UB, Riesch E, Djémié T, Müller S, Møller RS, et al. De novo loss- or gain-of-function mutations in KCNA2 cause epileptic encephalopathy. Nat Genet. 2015:47:393-9.

100. Muona M, Berkovic SF, Dibbens LM, Oliver KL, Maljevic S, Bayly MA, et al. A recurrent de novo mutation in $\mathrm{KCNC1}$ causes progressive myoclonus epilepsy. Nat Genet. 2015;47:39-46.

101. Richards MC, Heron SE, Spendlove HE, Scheffer IE, Grinton B, Berkovic SF, et al. Novel mutations in the KCNQ2 gene link epilepsy to a dysfunction of the KCNQ2-calmodulin interaction. J Med Genet. 2004;41:e35.

102. Singh NA, Westenskow P, Charlier C, Pappas C, Leslie J, Dillon J, et al. KCNQ2 and KCNQ3 potassium channel genes in benign familial neonatal convulsions: expansion of the functional and mutation spectrum. Brain. 2003:126:2726-37.

103. Weckhuysen S, Ivanovic V, Hendrickx R, Van Coster R, Hjalgrim H, Møller RS, et al. Extending the KCNQ2 encephalopathy spectrum: clinical and neuroimaging findings in 17 patients. Neurology. 2013;81:1697-703.

104. Allen NM, Mannion M, Conroy J, Lynch SA, Shahwan A, Lynch B, et al. The variable phenotypes of KCNQ-related epilepsy. Epilepsia. 2014;55:e99-105

105. Heron SE, Smith KR, Bahlo M, Nobili L, Kahana E, Licchetta L, et al. Missense mutations in the sodium-gated potassium channel gene KCNT1 cause severe autosomal dominant nocturnal frontal lobe epilepsy. Nat Genet. 2012:44:1188-90.

106. Ishii A, Shioda M, Okumura A, Kidokoro H, Sakauchi M, Shimada S, et al. A recurrent KCNT1 mutation in two sporadic cases with malignant migrating partial seizures in infancy. Gene. 2013;531:467-71.

107. McTague A, Appleton R, Avula S, Cross JH, King MD, Jacques TS, et al. Migrating partial seizures of infancy: expansion of the electroclinical, radiological and pathological disease spectrum. Brain. 2013;136:1578-91. 
108. Vaher U, Nõukas M, Nikopensius T, Kals M, Annilo T, Nelis M, et al. De novo SCN8A mutation identified by whole-exome sequencing in a boy with neonatal epileptic encephalopathy, multiple congenital anomalies, and movement disorders. J Child Neurol. 2014;29:NP202-6.

109. Nakamura K, Kodera H, Akita T, Shiina M, Kato M, Hoshino H, et al. De novo mutations in GNAO1, encoding a Gao subunit of heterotrimeric G proteins, cause epileptic encephalopathy. Am J Hum Genet. 2013;93:496-505.

110. Berryer MH, Hamdan FF, Klitten LL, Møller RS, Carmant L, Schwartzentruber J, et al. Mutations in SYNGAP1 cause intellectual disability, autism, and a specific form of epilepsy by inducing haploinsufficiency. Hum Mutat. 2013;34:385-94.

111. Hamdan FF, Daoud H, Piton A, Gauthier J, Dobrzeniecka S, Krebs MO, et al De novo SYNGAP1 mutations in nonsyndromic intellectual disability and autism. Biol Psychiatry. 2011;69:898-901.

112. Afawi Z, Mandelstam S, Korczyn AD, Kivity S, Walid S, Shalata A, et al. TBC1D24 mutation associated with focal epilepsy, cognitive impairment and a distinctive cerebro-cerebellar malformation. Epilepsy Res. 2013;105:240-4.

113. Corbett MA, Bahlo M, Jolly L, Afawi Z, Gardner AE, Oliver KL, et al. A focal epilepsy and intellectual disability syndrome is due to a mutation in TBC1D24. Am J Hum Genet. 2010;87:371-5.

114. Falace A, Filipello F, La Padula V, Vanni N, Madia F, De Pietri TD, et al. TBC1D24, an ARF6-interacting protein, is mutated in familial infantile myoclonic epilepsy. Am J Hum Genet. 2010;87:365-70.

115. Guven A, Tolun A. TBC1D24 truncating mutation resulting in severe neurodegeneration. J Med Genet. 2013;50:199-202.

116. Milh M, Falace A, Villeneuve N, Vanni N, Cacciagli P, Assereto S, et al. Novel compound heterozygous mutations in TBC1D24 cause familial malignant migrating partial seizures of infancy. Hum Mutat. 2013;34:869-72.

117. Poulat AL, Ville D, de Bellescize J, André-Obadia N, Cacciagli P, Milh M, et al. Homozygous TBC1D24 mutation in two siblings with familial infantile myoclonic epilepsy (FIME) and moderate intellectual disability. Epilepsy Res. 2015;111:72-7.

118. Strazisar BG, Neubauer D, Paro Panjan D, Writzl K. Early-onset epileptic encephalopathy with hearing loss in two siblings with TBC1D24 recessive mutations. Eur J Paediatr Neurol. 2015;19:251-6.

119. Vanni N, Fruscione F, Ferlazzo E, Striano P, Robbiano A, Traverso M, et al. Impairment of ceramide synthesis causes a novel progressive myoclonus epilepsy. Ann Neurol. 2014;76:206-12.

120. Thevenon J, Milh M, Feillet F, St-Onge J, Duffourd Y, Jugé C, et al. Mutations in SLC13A5 cause autosomal-recessive epileptic encephalopathy with seizure onset in the first days of life. Am J Hum Genet. 2014;95:113-20.

121. Cohen R, Basel-Vanagaite L, Goldberg-Stern H, Halevy A, Shuper A, Feingold-Zadok $M$, et al. Two siblings with early infantile myoclonic encephalopathy due to mutation in the gene encoding mitochondrial glutamate/ $\mathrm{H}^{+}$symporter SLC25A22. Eur J Paediatr Neurol. 2014;18:801-5.

122. Molinari F, Kaminska A, Fiermonte G, Boddaert N, Raas-Rothschild A, Plouin $P$, et al. Mutations in the mitochondrial glutamate carrier SLC25A22 in neonatal epileptic encephalopathy with suppression bursts. Clin Genet. 2009;76:188-94.

123. Molinari F, Raas-Rothschild A, Rio M, Fiermonte G, Encha-Razavi F, Palmieri L, et al. Impaired mitochondrial glutamate transport in autosomal recessive neonatal myoclonic epilepsy. Am J Hum Genet. 2005;76:334-9.

124. Poduri A, Heinzen EL, Chitsazzadeh V, Lasorsa FM, Elhosary PC, LaCoursiere CM, et al. SLC25A22 is a novel gene for migrating partial seizures in infancy. Ann Neurol. 2013;74:873-82.

125. Kodera H, Nakamura K, Osaka H, Maegaki Y, Haginoya K, Mizumoto S, et al. De novo mutations in SLC35A2 encoding a UDP-galactose transporter cause early-onset epileptic encephalopathy. Hum Mutat. 2013;34:1708-14.

126. Ng BG, Buckingham KJ, Raymond K, Kircher M, Turner EH, He M, et al. Mosaicism of the UDP-galactose transporter SLC35A2 causes a congenital disorder of glycosylation. Am J Hum Genet. 2013;92:632-6.

127. Alazami AM, Hijazi H, Kentab AY, Alkuraya FS. NECAP1 loss of function leads to a severe infantile epileptic encephalopathy. J Med Genet. 2014;51:224-8.

128. Rohena L, Neidich J, Truitt Cho M, Gonzalez KD, Tang S, Devinsky O, et al. Mutation in SNAP25 as a novel genetic cause of epilepsy and intellectual disability. Rare Dis. 2013;1:e26314.

129. Schubert J, Siekierska A, Langlois M, May P, Huneau C, Becker F, et al. Mutations in STX1B, encoding a presynaptic protein, cause fever-associated epilepsy syndromes. Nat Genet. 2014;46:1327-32.
130. Deprez L, Weckhuysen S, Holmgren P, Suls A, Van Dyck T, Goossens D, et al. Clinical spectrum of early-onset epileptic encephalopathies associated with STXBP1 mutations. Neurology. 2010;75:1159-65.

131. Hamdan FF, Gauthier J, Dobrzeniecka S, Lortie A, Mottron L, Vanasse M, et al. Intellectual disability without epilepsy associated with STXBP1 disruption. Eur J Hum Genet. 2011;19:607-9.

132. Hamdan FF, Piton A, Gauthier J, Lortie A, Dubeau F, Dobrzeniecka S, et al. De novo STXBP1 mutations in mental retardation and nonsyndromic epilepsy. Ann Neurol. 2009;65:748-53.

133. Mastrangelo M, Peron A, Spaccini L, Novara F, Scelsa B, Introvini $P$, et al. Neonatal suppression-burst without epileptic seizures: expanding the electroclinical phenotype of STXBP1-related, early-onset encephalopathy. Epileptic Disord. 2013;15:55-61.

134. Michaud JL, Lachance M, Hamdan FF, Carmant L, Lortie A, Diadori P, et al. The genetic landscape of infantile spasms. Hum Mol Genet. 2014;23:4846-58

135. Otsuka M, Oguni $H$, Liang JS, Ikeda H, Imai K, Hirasawa K, et al. STXBP1 mutations cause not only Ohtahara syndrome but also West syndromeresult of Japanese cohort study. Epilepsia. 2010;51:2449-52.

136. Saitsu H, Kato M, Mizuguchi T, Hamada K, Osaka H, Tohyama J, et al. De novo mutations in the gene encoding STXBP1 (MUNC18-1) cause early infantile epileptic encephalopathy. Nat Genet. 2008;40:782-8.

137. Saitsu H, Kato M, Okada I, Orii KE, Higuchi T, Hoshino H, et al. STXBP1 mutations in early infantile epileptic encephalopathy with suppression-burst pattern. Epilepsia. 2010;51:2397-405

138. Nakashima M, Saitsu H, Takei N, Tohyama J, Kato M, Kitaura H, et al. Somatic mutations in the MTOR gene cause focal cortical dysplasia type Ilb. Ann Neurol. 2015. doi:10.1002/ana.24444.

139. Abdel-Salam G, Thoenes M, Afifi HH, Körber F, Swan D, Bolz HJ. The supposed tumor suppressor gene WWOX is mutated in an early lethal microcephaly syndrome with epilepsy, growth retardation and retinal degeneration. Orphanet J Rare Dis. 2014;9:12.

140. Ben-Salem S, Al-Shamsi AM, John A, Ali BR, Al-Gazali L. A novel whole exon deletion in WWOX gene causes early epilepsy, intellectual disability and optic atrophy. J Mol Neurosci. 2015;56:17-23.

141. Mallaret M, Synofzik M, Lee J, Sagum CA, Mahajnah M, Sharkia R, et al. The tumour suppressor gene WWOX is mutated in autosomal recessive cerebellar ataxia with epilepsy and mental retardation. Brain. 2014;137:411-9.

142. Mignot C, Lambert L, Pasquier L, Bienvenu T, Delahaye-Duriez A, Keren B, et al. WWOX-related encephalopathies: delineation of the phenotypical spectrum and emerging genotype-phenotype correlation. J Med Genet. 2015;52:61-70 